\title{
Carcinoma de células escamosas. A propósito de un caso
}

\author{
Squamous cell carcinoma: a case report
}

\author{
Felicitas Matilda Tocino ${ }^{1,2}$, Melkys Caroline ${ }^{1}$
}

\author{
${ }^{1}$ Diplomado en podología. \\ podologapoblenou@hotmail.com \\ ${ }^{2}$ Diplomada en Enfermería. \\ melkys_16@hotmail.com
}

Correspondencia:

c/ Marià Aguiló 72, bajos.

E-08005 Barcelona

Correo electrónico: podologapoblenou@hotmail.com,melkys_16@hotmail.com

Fecha de recepción: 8 de noviembre de 2012

Fecha de aceptación: 22 de abril de 2013

Los autores declaran no tener ningún tipo de interés económico o comercial.

\section{RESUMEN}

El pie no está libre de ser afectado por lesiones dérmicas con mayor o menor grado de malignidad. Con este trabajo pretendemos que el lector se familiarice con el Cáncer de células escamosas o epidermoide. Un tipo de cáncer de piel que representa un alto porcentaje de incidencia y así pueda reconocerlo, diagnosticarlo y si es el caso tratarlo o derivarlo a otros especialistas.

Presentamos el caso clínico de una mujer afectada por un carcinoma de células escamosas en el quinto dedo del pie derecho, a la cual practicamos como tratamiento definitivo la amputación del dedo. Para la obtención de un diagnóstico diferencial optamos por realizar una biopsia previa mediante la técnica de Punch y tras la cirugía se manda a analizar la pieza anatómica amputada que confirma el diagnóstico e informa del pronóstico de la enfermedad. Palabras clave: carcinoma de células escamosas.

\begin{abstract}
The foot could be affected by skin lesions with varying degrees of malignancy. In this paper we report a case of squamous cell cancer or squamous cell carcinoma. It is a type of skin cancer that has a high percentage of incidence and thus can recognize, diagnose and treat it if necessary or refer you to other specialists.

We report the case of a woman affected by squamous cell carcinoma in the right fifth toe, which was treated with amputation of fifth toe. To obtain a differential diagnosis we decided to perform a previous biopsy using the technique of Punch and after surgery the specimen were sent to pathologist for testing and confirming the diagnosis and reports the prognosis.
\end{abstract}

Key words: squamous cell carcinoma.

Referencia normalizada: Matilda Tocino, F., Caroline, M. Carcinoma de células escamosas. A propósito de un caso. Rev. Int. Cienc. Podol. 2014; 8(1): 37-44.

Sumario: 1. Introducción, 2. Etiología. 3. Etiopatogenia, 4. Manifestaciones clínicas, 5. Diagnóstico, 6. Tratamiento, 7. Pronóstico, 8. Conclusión, 9. Caso clínico, 10. Descripción de la técnica quirúrgica, 11. Conclusión, Bibliografía. 


\section{INTRODUCCIÓN}

El carcinoma de células escamosas (CCE) es un tipo de cáncer que se origina en la capa intermedia de la epidermis, derivado de los queratinocitos. Estudios sugieren que el riesgo de carcinoma invasivo es alrededor de $3 \%{ }^{1}$.

También denominado Carcinoma epidermoide o Carcinoma espinocelular.

En USA se diagnostican más de 250000 nuevos casos anuales. Tienen el doble de frecuencia en los hombres que en las mujeres y raramente aparece antes de los 50 años, teniendo su mayor incidencia a los $70^{2}$. La baja prevalencia de tumores en el pie, apenas un $4 \% \%^{3}$, reduce las posibilidades de encontrarnos con este tipo de lesión en el pie. El CCE es el segundo cáncer de piel más frecuente después del carcinoma basocelular y entre ambos representan el $95 \%$ de los cánceres cutáneos no melanoma 5 .

\section{ETIOLOGIA}

La exposición crónica a la luz ultravioleta, sobre todo de origen solar, es la principal causa. También predispone el consumo de tabaco y alcohol (cuando afecta a la mucosa oral), las radiaciones ionizantes, la exposición a carcinógenos químicos como el arsénico, el alquitrán, los cromados y el antraceno, así como determinados Síndromes genéticos (Xeroderma pigmemntoso, albinismo oculocutáneo, Sindrome de Bazex...)

El virus de papiloma humano tipo 5 (VH5) está también implicado en el desarrollo del CCE. Aunque no está demostrado los investigadores sospechan que hay más virus que pueden estar implicados ${ }^{2,4}$.

Se presenta en piel y mucosas, en cualquier parte del cuerpo, pero son más comunes en las zonas expuestas al sol como el borde de la oreja, el labio inferior, la cara, cuero cabelludo calvo y manos. Con mayor riesgo de contraer la enfermedad las personas con piel clara, cabellos y ojos claros. Los UVB pueden predisponer a la piel no solo por daño del DNA, sino por lesión de las células de Langerhans ${ }^{4}$.

El VIH y otras enfermedades de deficiencia inmunitaria, la quimioterapia, los medicamentos contra el rechazo usados en trasplantes y en general todas las situaciones que debilitan el sistema inmunitario hacen más susceptibles a las personas a padecer la enfermedad dérmicas porque la piel es más sensible a la exposición solar y el déficit inmunitario dificulta la lucha contra la enfermedad ${ }^{5}$.

\section{ETIOPATOGENIA}

El CCE frecuentemente comienza en una zona de queratosis actínica, así como enfermedades preexistentes de la piel de cualquier etiología (como el xeroderma pigmentoso, patología hereditaria altamente sensible a rayos UV), quemaduras, úlceras o cicatrices. Raramente se desarrolla sobre piel previamente sana y normal.

Se caracteriza por nidos irregulares de células epidérmicas que invaden la dermis en distintos grados y muestran células atípicas, mitosis y queratización individual exagerada o formación de quistes.

Según la clasificación de Broders, se distinguen 4 grados histológicos de diferenciación celular. Estos grados histológicos se traducen clínicamente por diferentes lesiones, el grado I (Figura 1) donde las células están bien diferenciadas hasta el grado IV (Figura 2), donde se incluyen las células más indiferenciadas o anaplásicas.

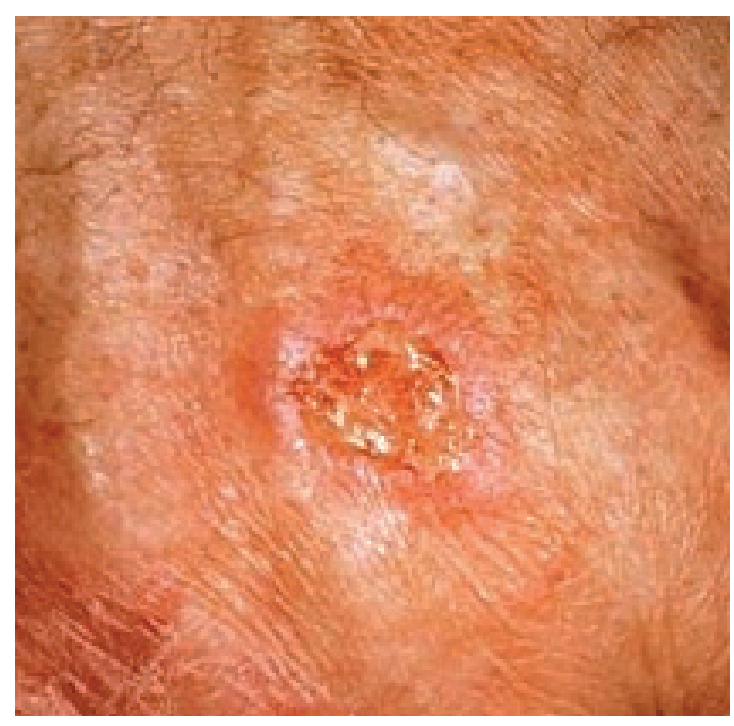

Figura 1. Grado I: Lesión escamosa. 


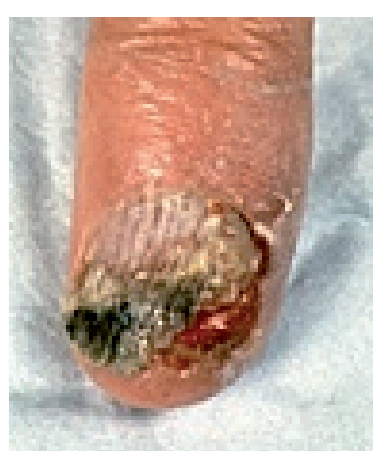

Figura 2. Grado IV: llaga que no cura.

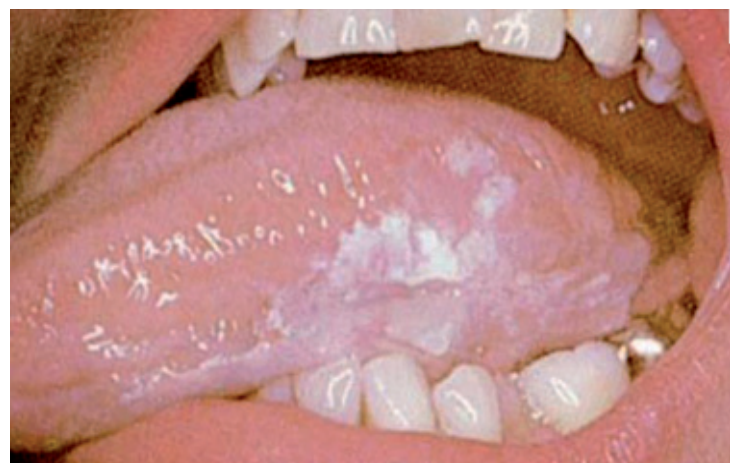

Figura 3. Placa blanquecina típica de leucoplasia.

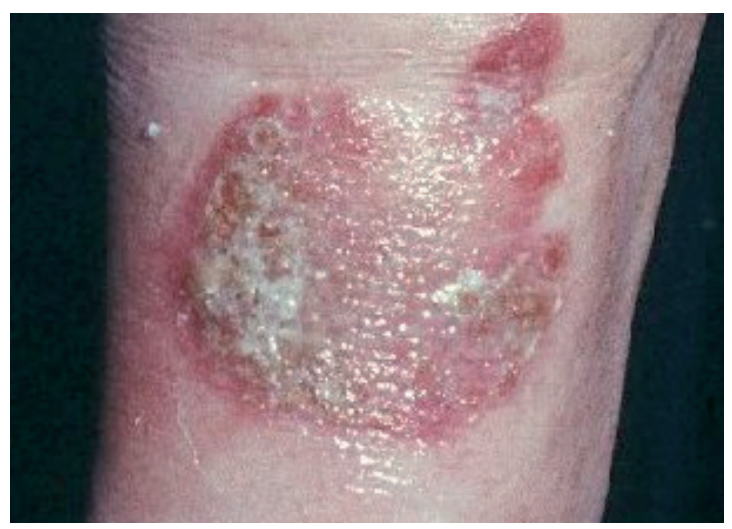

Figura 4. Enfermedad de Bowen en la pierna.

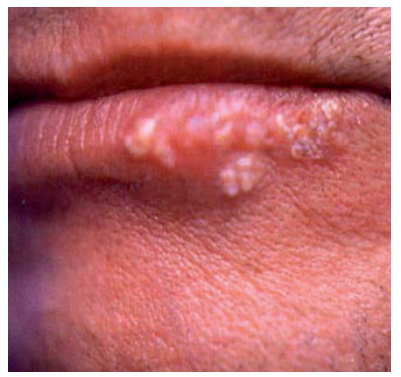

Figura 5. Lesión papilomatosa $\mathrm{i}$ rregular.

\section{MANIFESTACIONES CLIINICAS}

El CCE comienza como una zona roja con superficie costrosa, descamativa, que no cura. A medida que crece, el tumor puede volverse nodular y duro y en ocasiones presentar una superficie verrugosa.

Generalmente los CCE sólo afectan a la epidermis y dermis (in situ). Una vez atraviesa la membrana basal epitelial, el tumor adquiriere la capacidad de invadir la grasa, el músculo, el hueso o el cartílago locales y en algunas ocasiones se extienden (metastatizan los ganglios regionales) y pueden ser mortales 5 .

Tiene distintas presentaciones clínicas:

- Queratosis actínicas o solares: Es el CCE in situ más frecuente. Presenta pequeñas placas eritomatosas, escamosas y levemente elevadas, que varían de color del marrón hasta el rojo. Se presentan en zonas expuestas al sol, mayormente en personas mayores.

- Leucoplasia: Es también un CCE in situ que se presenta en forma de placas blancas en la lengua, encías, mejillas o en cualquier otra parte de la boca (Figura 3). Relacionado con el consumo frecuente de alcohol o tabaco.

- Enfermedad de Bowen: es una forma temprana de CCE in situ. La piel afectada es de color rojo-padusco, escamosa o costrosa, plana y a veces similar a placas de psoriasis, dermatitis o a una infección micótica (Figura 4)

- Carcinoma escamoso invasivo (espinocelular): en los estadios iniciales no se diferencia de los distintos tipos de CCE in situ. El diagnóstico diferencial es histiopatológico. En casos evolucionados aparecen nódulos o masas tumorales ulceradas que se cubren con costras, frecuentemente hemorrágicas. Metastatizan vía linfática y con menor frecuencia vía hemática.

- Carcinoma verrucoso: es una variedad del CCE bien diferenciado, de aspecto hiperqueratósico y papilomatoso similar a las verrugas. La localización más frecuente es la boca (papilomatosis oral florida, Figura 5), la zona genitoanal (condiloma gigante), en el lecho ungueal y planta del pie (epitelioma coniculatum, Figura 6). Se caracteri- 


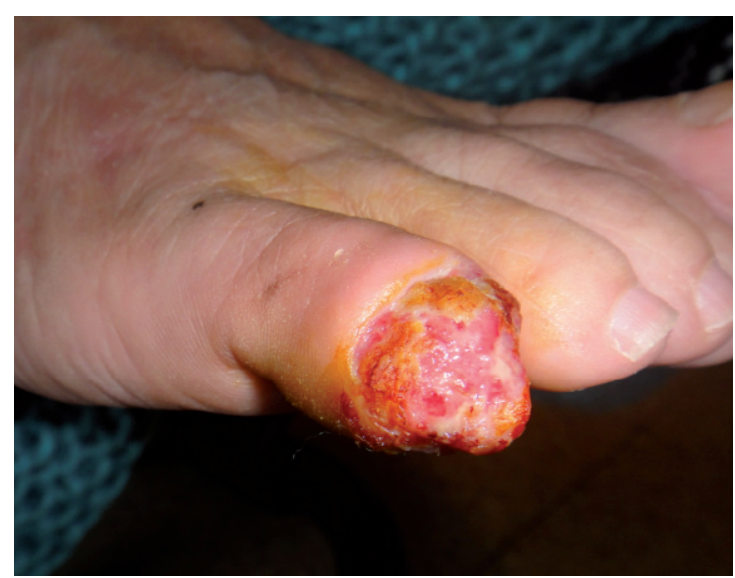

Figura 6. Carcinoma $\mathrm{CE}$ en lecho ungueal.

za porque es de lento crecimiento y tiene un alto riesgo de metástasis en pacientes inmunodeprimidos. Se ha incluir en la exploración de estos pacientes los ganglios linfáticos regionales y otras pruebas complementarias.

\section{DIAGNÓSTICO}

Ante una lesión dérmica sospechosa los clínicos debemos tener claro que el diagnóstico definitivo se realiza mediante una biopsia de la lesión para estudio anatomopatológico.

La extirpación de los ganglios linfáticos regionales se recomienda en algunos carcinomas de células escamosas muy grandes o profundamente invasivos, así como en aquellos casos en los que éstos se sienten aumentados de tamaño o duros a la palpación. En estos casos los pacientes han de ser derivados al especialista ya que una vez extirpados y analizados, si contienen células cancerosas, el tratamiento ha de ser sistémico.

El antígeno SCC se asocia a los CCE. Sus valores normales llegan hasta $2,75 \mathrm{ng} / \mathrm{mL}$. Los resultados falsos positivos se asocian a insuficiencia renal, psoriasis, pénfigo, eccemas y neumopatías (tuberculosis). El SCC es un marcador tumoral de las neoplasias epidermoides, principalmente de cérvix, pulmón, laringe y ano, siendo de interés como indicador pronóstico, en la detección precoz de recidiva y en la monitorización terapéutica ${ }^{3}$. Su principal utili- dad en esta neoplasia de células escamosas es como indicador precoz de recidiva.

\section{TRATAMIENTO}

La mayoría de los CCE se encuentran y tratan en una etapa temprana, cuando pueden ser extirpados o destruidos con métodos de tratamiento local. En pocas ocasiones se propagan a los ganglios linfáticos o a áreas distantes. Si esto ocurre, puede que sea necesario administrar tratamiento adicional con radioterapia y/o quimioterapia ${ }^{2,6}$.

1. Electrodesecación y legrado: útil en el caso de tumores pequeños pero no se recomienda para tumores grandes en cuyo caso sería preciso una excisión quirúrgica amplia.

2. Criocirugía: se utiliza para algunos carcinomas de células escamosas en etapas iniciales, pero no se recomienda para tumores invasivos más grandes, ni para tumores localizados en ciertas partes de la nariz, las orejas, los párpados, el cuero cabelludo o las piernas.

3. Cirugía de Mohs: tiene la mejor tasa de curación. Resulta especialmente beneficiosa en el tratamiento de CCE de más de $2 \mathrm{~cm}$ de diámetro ${ }^{2}$ o con bordes pobremente definidos, para tumores que han reaparecido después de otros tratamientos, para un cáncer que se está extendiendo a lo largo de los nervios debajo de la piel y para un cáncer localizado en ciertas áreas de la cara o del área genital.

4. Radioterapia: es una buena opción especialmente en áreas en las que se dificulta la cirugía (los párpados, las orejas o la nariz), para pacientes que no pueden tolerar la cirugía, como tratamiento paliativo o como parte del tratamiento adyuvante de los CCE grado III (con ganglios afectados).

La radiación también se usa para el tratamiento de los cánceres que han recidivado después de la cirugía y han crecido demasiado o han invadido tan profundamente como para ser extirpados quirúrgicamente. No recomendado en el carcinoma verrugoso (salvo en casos paliativos)

5. Quimioterapia sistémica: es una opción para aquellos pacientes con un CCE que 
se ha extendido a los ganglios linfáticos o a órganos distantes. En algunos casos, se puede combinar con cirugía o radioterapia.

6. Quimioterapia tópica: como el 5- fluorouracilo indicado en la queratosis actínica, aunque su uso hoy genera controversia.

7. Modificadores de la respuesta biológica: cremas de imiquimod que estimula el sistema inmunitario. Interferon infiltrado intralesional.

8. Otros: Láser $\mathrm{CO} 2$, terapia fotodinámica, radiación.

\section{PRONÓSTICO}

Generalmente, los CCE sólo afectan a la zona que los rodea penetrando más profundamente en los tejidos cercanos. Pero otros metastatizan, entre el 0,5 al $5,2 \%^{2}$ y pueden ser mortales ${ }^{4,5,6}$.

Aunque varían las interpretaciones se cree que a mayor diferenciación menor tendencia invasiva y por tanto mejor pronóstico. Las lesiones mayores de $2 \mathrm{~cm}$ y con una profundidad superior a los $4 \mathrm{~mm}$ presentan un mal pronóstico.

La recidiva local y las metástasis están relacionadas con: el tratamiento elegido, tratamientos previos, la localización, el tamaño, la profundidad, la diferenciación histolólogica, evidencia de afectación perineural, factores de riesgo e inmunosupresión del paciente.

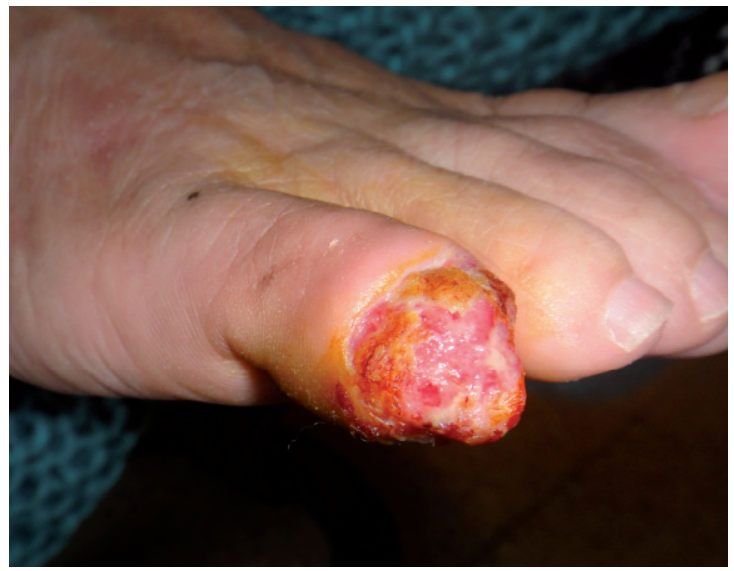

Figura 7. Úlcera sangrante de 18 meses de evolución.

\section{CONCLUSIÓN}

El CCE es un cáncer que se origina en la capa intermedia de la epidermis.

Reconocer las causas y las diferentes formas clínicas en que se presenta es imprescindible para realizar un diagnóstico precoz y tener mayor éxito en el tratamiento. Los podólogos como clínicos y sanitarios que nos encontramos frecuentemente en nuestras consultas con patologías dérmicas debemos saber reconocerlas, diagnosticarlas, conocer las diferentes alternativas de tratamiento y en su caso realizarlo adecuadamente.

\section{CASO CLÍNICO}

Mujer de 80 años que acude a nuestra consulta por presentar lesión sangrante no dolorosa en $5^{\circ}$ dedo del pie dcho de 18 meses de evolución.

Como antecedentes médicos de interés presenta como única patología Alzheimer en estadío avanzado que la hace dependiente para las actividades diarias de la vida.

En la inspección observamos lesión exofítica, friable y sangrante en la zona distal del $5^{\circ}$ dedo que ocupa prácticamente la falange distal, erosionando la uña (Figura 7).

Se decide realizar biopsia mediante la técnica de punción con Punch (Figura 8). El resultado era previsible por el aspecto de la lesión, Carcinoma de células escamosas.

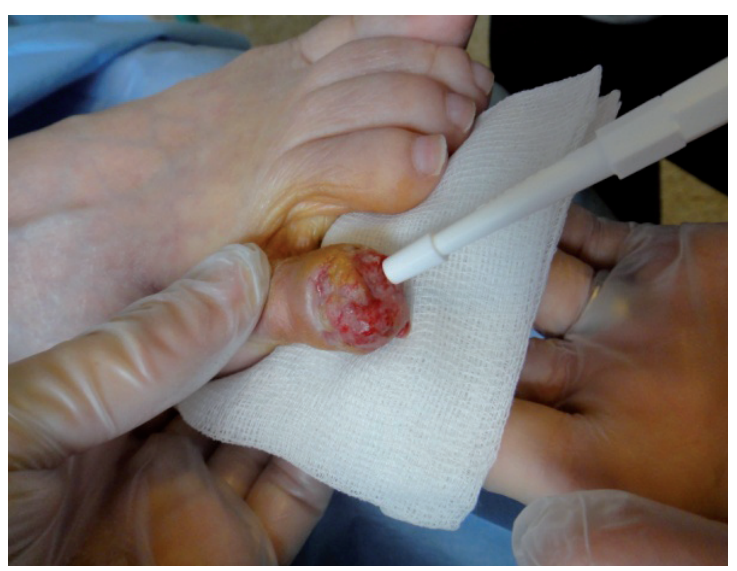

Figura 8. Toma de muestra para biopsia. 

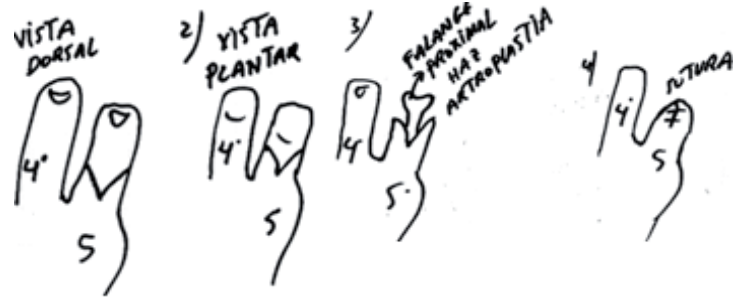

Figura 9. Diseño de la incisión.

Los carcinomas de células escamosas detectados en una etapa temprana y extirpados rápidamente casi siempre son curables y causan un daño mínimo. Sin embargo si se dejan sin tratar, penetran en tejidos subyacentes y provocan metástasis en tejidos y órganos distantes con un resultado fatal. Nuestra paciente no presentaba a la palpación edema ni induración de los ganglios inguinales de la extremidad afectada.

Ante el tamaño y la evolución de la lesión después de conocer el resultado de la anatomía patológica, de todas las opciones de tratamiento nos decantamos por realizar cirugía de extirpación amplia, después de informar y consensuarlo con los tutores legales de la paciente. Se decide amputación del $5^{\circ}$ dedo mediante una artroplastia en la falange proximal del $5^{\circ}$ dedo, para preservar zona de inserción de músculos intrínsecos.

Siguiendo los protocolos de procedimientos quirúrgicos en nuestra consulta realizamos una analítica prequirúrgica, el hijo es el responsable de firmar el consentimiento informado, paso previo legal imprescindible. Entregamos también la Hoja informativa para los cuidados posquirúrgicos.

El diseño de la incisión es muy importante para evitar tensiones en la piel a la hora de sutu-

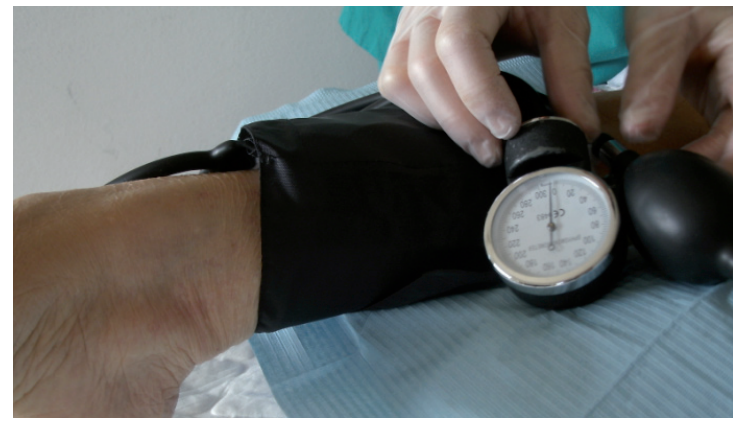

Figura 10. Hemostasia en el tobillo. rar que puedan provocar deshicencia o necrosis de los bordes. El corte tanto dorsal como plantarmente está diseñado en $\mathrm{V}$ con vértice proximal (Figura 9).

\section{DESCRIPCIÓN DE LA TÉCNICA QUIRÚRGICA}

Bajo anestesia troncular del $5^{\circ}$ dedo con Mepivacaína al $2 \%$ ( $4 \mathrm{cc}$ ) y hemostasia en tobillo con esfigmomanómetro a $240 \mathrm{mmHG}$, controlando que la cirugía no supere los 40 minutos, tiempo recomendado por la bibliografía para este tipo de hemostasia (Figura 10) se procede a la amputación distal del dedo.

Se realiza la incisión de la piel en varios cortes, sobre diáfisis de falanges proximal y media para exponer la art. Interfalángica a este nivel y liberarla a punta de bisturí (Figura11).

Realizamos después una artroplastia generosa de falange proximal (Figura 12) con el objetivo de ampliar al máximo la resección de la lesión. Terminamos con un buen lavado de la zona quirúrgica con suero fisiológico, suturando la incisión con puntos simples de seda $3 / 0$ y cubriéndolo con un vendaje semicompresivo de antepié (Figura13)

Las figuras 14 y 15 muestran respectivamente la herida quirúrgia a las $48 \mathrm{~h}$, que fue cuando se realizó la primera cura y a las 3 semanas de evolución cuando la paciente recibe el alta tras conocer el resultado de la anatomía patológica: CARCINOMA DE CELULAS ESCAMOSAS MODERADAMENTE DIFERENCIADO, INFILTRANDO DERMIS Y HUESO DE FALANGE. MARGENES DE RESECCION LIBRES DE TUMOR. Figura 16 y 17.

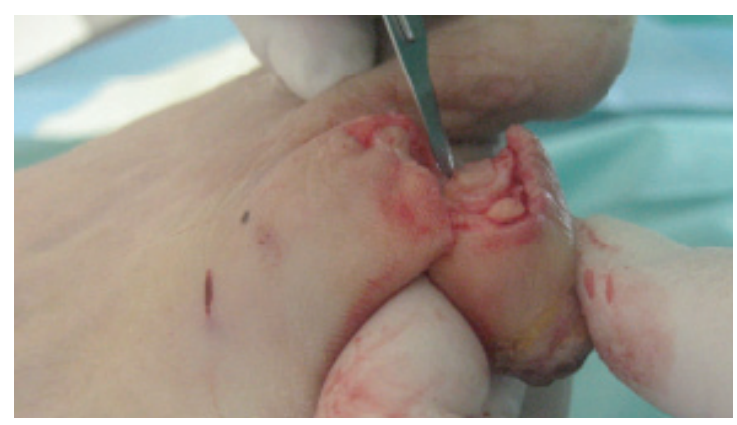

Figura 11. Liberación de la Art interfalángica. 

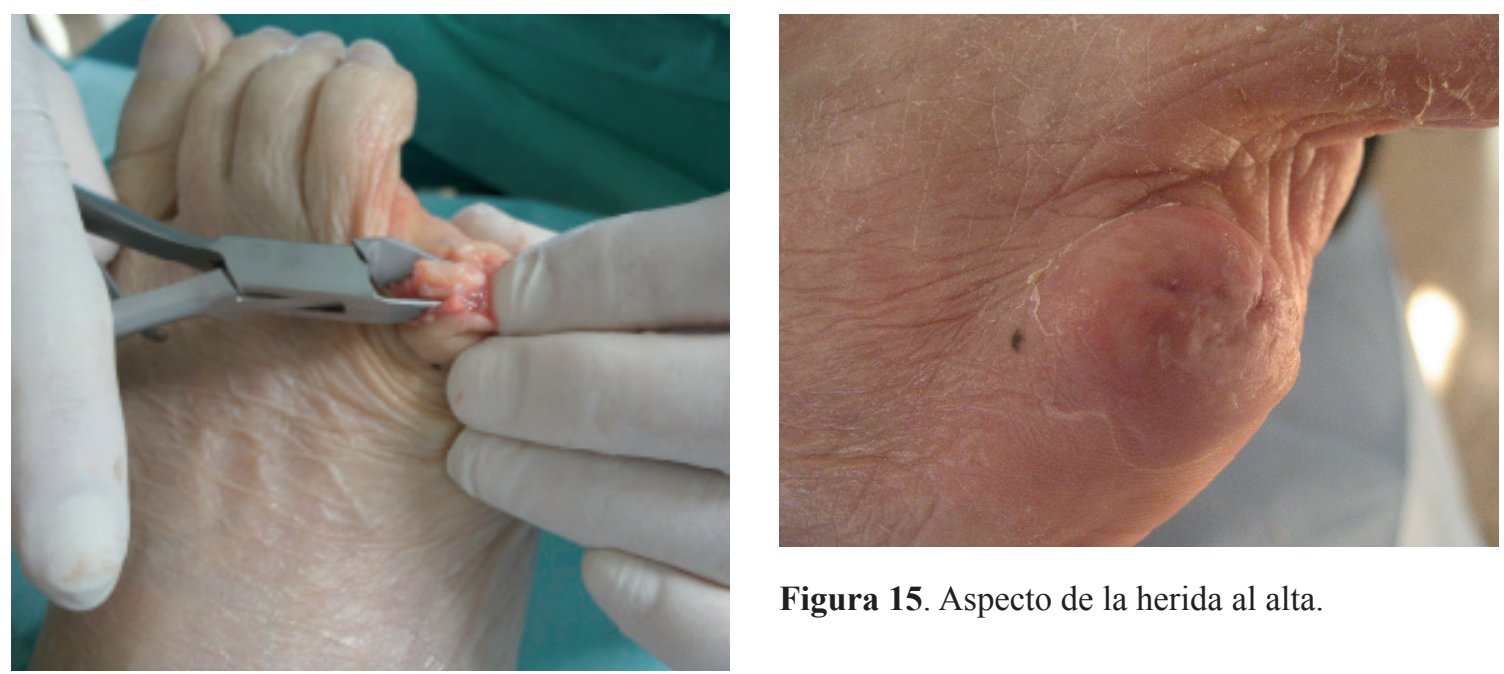

Figura 15. Aspecto de la herida al alta.

Figura 12. Artroplastia de la falange proximal.

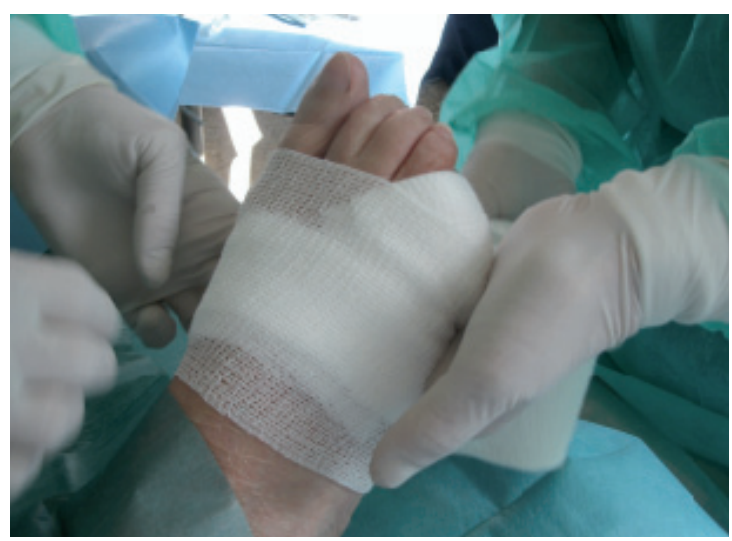

Figura 13. Vendaje semicompresivo de antepié.

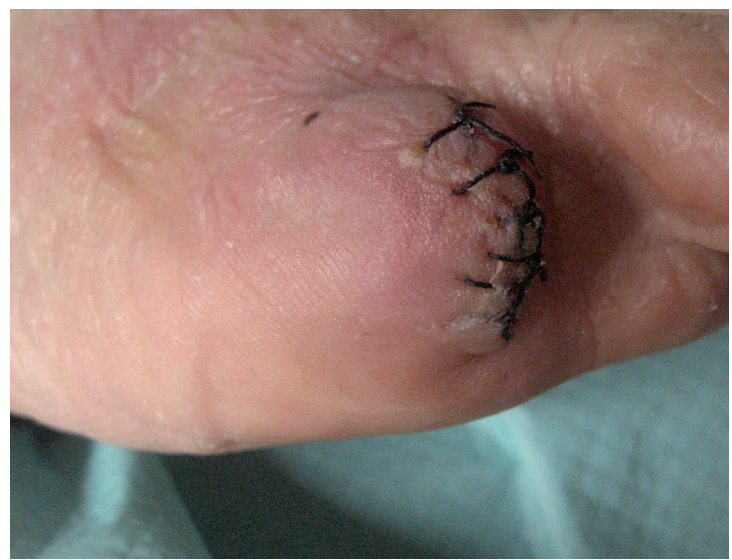

Figura 14. Aspecto de la herida en la primera cura.

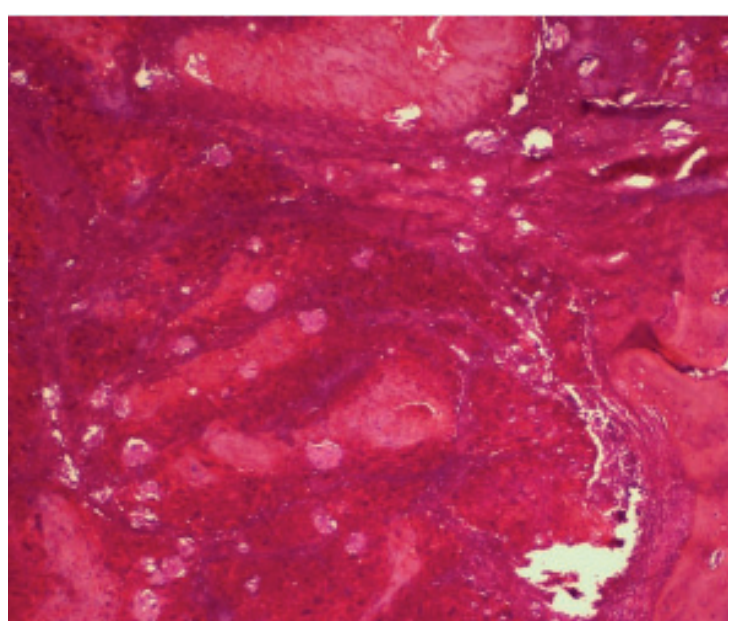

Figura 16. Detalle anatomo patológico.

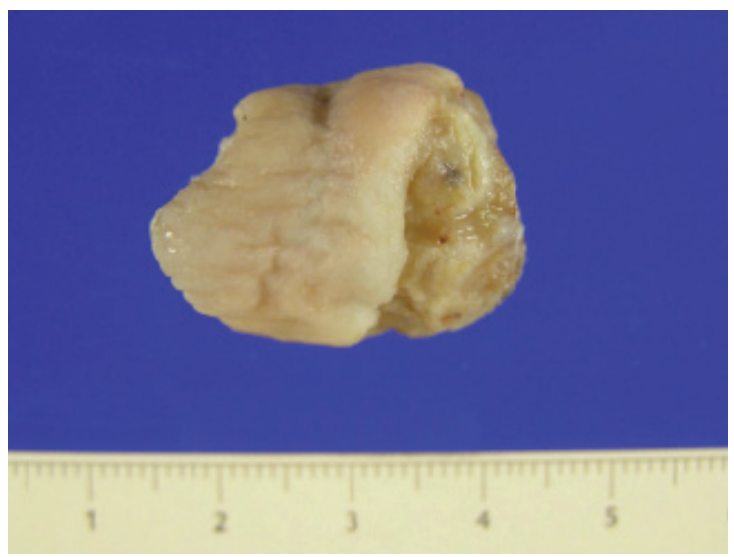

Figura 17. Pieza extirpada. 


\section{CONCLUSIÓN}

Los podólogos somos los profesionales sanitarios dedicados a la patología en el pie y esto incluye tener conocimientos importantes de dermatología, ya que el pie no está exento de sufrir una lesión de este tipo como hemos visto en el caso clínico.

Debemos estar preparados no sólo para diagnosticar sino para también tratar quirúrgicamente si fuese el caso, con una formación adecuada, o en su defecto para derivarlo a otro profesional junto con una buena Historia Clínica.
El mayor problema que se planteó en nuestro caso fue precisamente lo tarde que llegó a nuestra consulta derivado desde su Centro de Atención Primaria Sanitaria, después de más de 18 meses de evolución. Por lo que requirió un tratamiento muy agresivo, como es una amputación total del dedo.

Este tipo de cáncer de piel puede reaparecer aunque haya sido extirpado exitosamente la primera vez. Por ello es fundamental prestar especial atención a cualquier sitio tratado previamente.

Las medidas preventivas y los hábitos saludables son la mejor manera de evitarlas.

\section{BIBLIOGRAFÍA}

1. Mercuri M, Casa Dei R. Tumours in the foot. Foot and Ankle Surgery 2002. 8; 175-190.

2. Perry Robins. Carcinoma de células escamosas [Internet]. Skin Cancer Foundation; 2010 [cited 2012 Jun 15]. Available from: http://www.skincancer.org/es-ES/Carcinoma-De-Celulas-Escamosas.

3. Mustafa Ozdemir H, Yusuf Yildiz. Tumors of the foot and ankle: Analysisbof 196 cases. Foot and Ankle, 1997. 6 (36); 403-408.

4. Ferrandiz C. Dermatología Clínica.3º Ed. Madrid: Elsevier; 2008; 358-360.

5. Mascaró Galy JM, Bolognia JL. Dermatología, vol 2. $1^{\text {a }}$ Ed.Madrid: Elsevier ; 2004. 1677-1694.

6. Valero Salas JL. Tumores de la piel y de las partes blandas del pie. $1^{\text {a }}$ Ed. Madrid: EXA; 2003. Pag. 81-85. 